\title{
Calcified amorphous tumor of left atrium
}

\author{
Yi-Chang Lin, MD, Yi-Ting Tsai, MD, and Chien-Sung Tsai, MD
}

Video clip is available online.

A 74-year-old woman was referred to the Tri-Service General Hospital for evaluation of a calcified heart tumor that was identified incidentally on a routine chest radiograph (Figure 1). At the time of admission, she was not receiving any medications and had no family history of cardiovascular disease. Results of the physical examination were unremarkable. The echocardiogram had revealed normal left ventricular function and a mobile and hyperechoic tumor that measured $14 \times 27 \mathrm{~mm}$ and originated from the atrial septum. Laboratory data were within normal limits. The magnetic resonance images (Figures 2 and 3) of the heart showed that the mass was hypointense on T1-weighted images and did not demonstrate increased signal intensity with either T2 or delayed enhanced images. The tumor showed swinging motion on the coronary angiograms (Videos 1 and 2). Our patient underwent cardiac exploration and removal of the mass (Figure 4). Histologic examination revealed the mass to be composed of amorphous eosinophilic fibrin with dense calcification. No myxomatous tissue was seen. Six months after the operation, the patient was doing well.

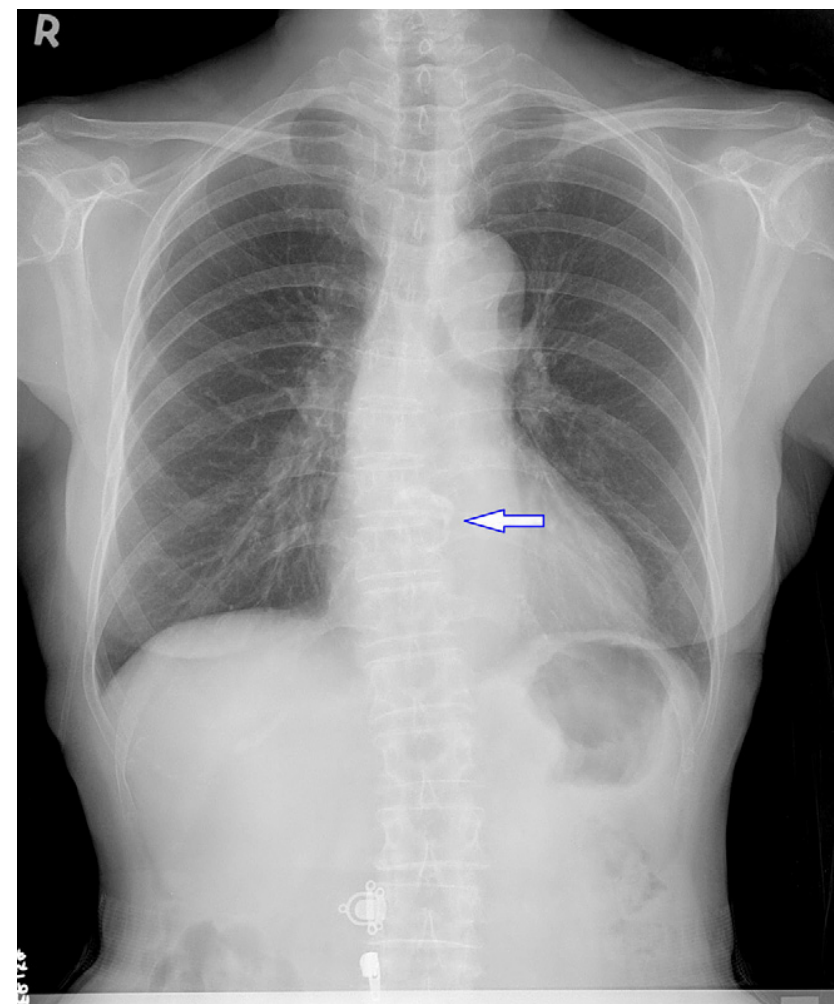

FIGURE 1. Chest radiograph showing calcified heart tumor (arrow).

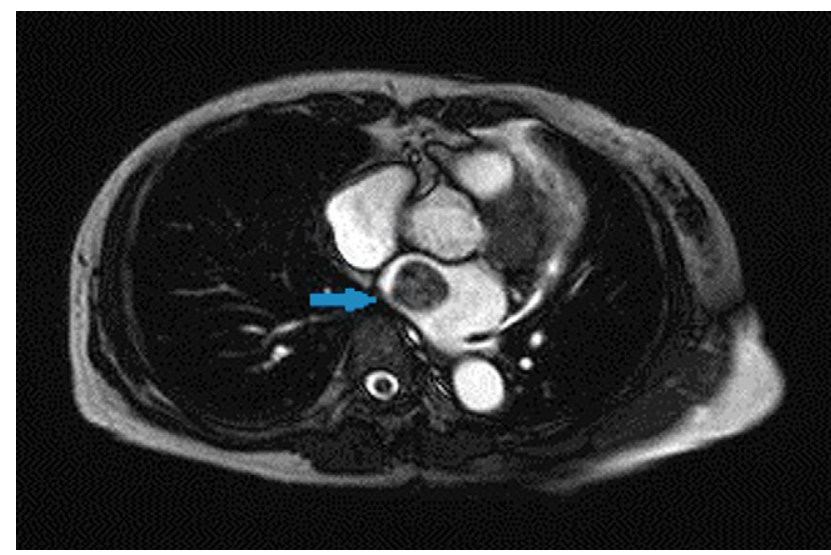

FIGURE 2. Magnetic resonance image of the mass (arrow).

From the Division of Cardiovascular Surgery, Department of Surgery, Tri-Service General Hospital, National Defense Medical Center, Taipei, Taiwan.

Disclosures: Authors have nothing to disclose with regard to commercial support.

Received for publication May 30, 2011; accepted for publication June 6, 2011; available ahead of print July 13, 2011.

Address for reprints: Chien-Sung Tsai, MD, Division of Cardiovascular Surgery, Department of Surgery, Tri-Service General Hospital, 325, Cheng-Kung Rd, 2nd section, Taipei 114, Taiwan, Republic of China (E-mail: sung1500@mail.ndmctsgh. edu.tw).

J Thorac Cardiovasc Surg 2011;142:1575-6

$0022-5223 / \$ 36.00$

Copyright $(9) 2011$ by The American Association for Thoracic Surgery

doi:10.1016/j.jtcvs.2011.06.003 

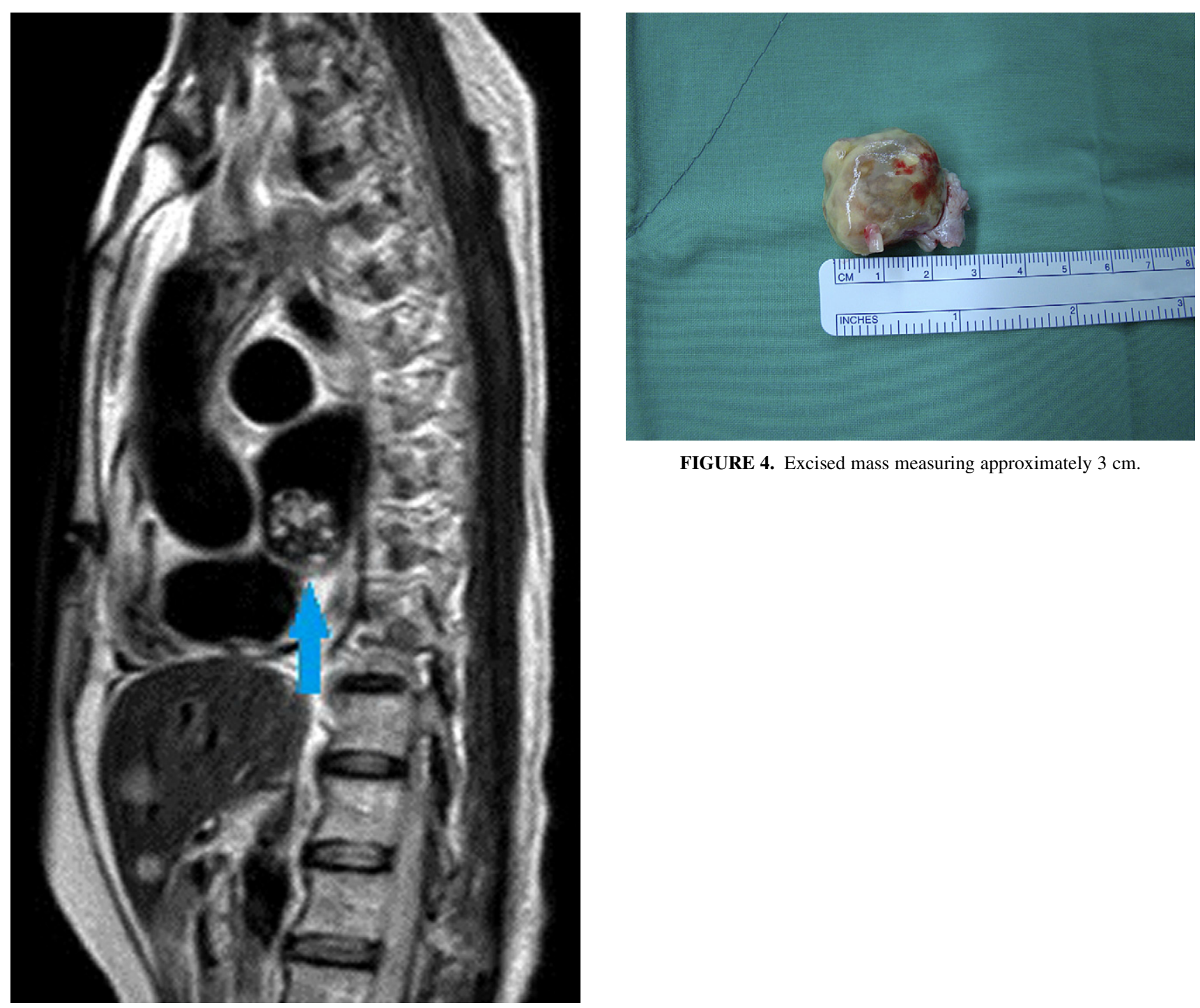

FIGURE 4. Excised mass measuring approximately $3 \mathrm{~cm}$.

FIGURE 3. Magnetic resonance image of the mass (arrow). 